Wissenswertes fehle, und gebe im Allgemeinen nur zur Zeit Feststehendes. Das Buch soll aber im eigentlichen Sinne des Wortes auch ein Hand- und Nachschlagebuch für den praktischen Arzt sein, das ihm ermöglicht die besprochenen Verletzungen lege artis zu erkennen und $z u$ behandeln, ohne in den Lehrbüchern sich erst das unbedingt Notwendige heraussuchen zu müssen. Grade die in Rede stehenden Verletzungen sind von so eminent praktischer Bedeutung und ein Versehen in der Diagnose oder Behandlung von oft zeitlebens üblen Folgen, so dass die Abfassung eines kurzen aber alles Wesentliche umfassenden Lehrbuches gerade für den Arzt gewiss gerechtfertigt erscheint. Wenn es mir mit den folgenden Blättern gelungen ist für Studierende, Aerzte und Patienten etwas Nützliches geschaffen $z u$ haben, so ist der Zweck reichlich erfüllt.

\title{
Vorwort zur II. Auflage.
}

In der vorliegenden II. Auflage des Compendiums habe ich es mir vor Allem angelegen sein lassen den berechtigten Wtinschen der Kritiken der I. Auflage nachzukommen. Der allgemeine Teil ist erweitert und es sind Zeichnungen hinzugefügt. In der Beschreibung der einzelnen Verrenkungen habe ich im Wesentlichen nichts geändert, da ich den Charakter eines Compendiums beibehalten wollte. Ich bemerke jedoch ausdrücklich, dass sich beide Bücher - über Luxationen und Fracturen - gegenseitig ergänzen sollen. 